\title{
Effect of Titanium Addition on Behavior of Medium Carbon Steel
}

\author{
Hoda S. El-Faramawy, Saeed N. Ghali", Mamdouh M. Eissa \\ Steel Technology Department, Central Metallurgical R \& D Institute (CMRDI), Cairo, Egypt \\ Email: *a3708052@yahoo.com
}

Received July 10, 2012; revised August 15, 2012; accepted August 31, 2012

\begin{abstract}
This work aims at investigating the influence of titanium addition on behavior of medium carbon steel. Three types of medium carbon steel with different titanium content and one reference steel titanium free were produced in $100 \mathrm{~kg}$ induction furnace. Titanium addition was increased up to $0.230 \%$. The produced steels were forged at start temperature $1150^{\circ} \mathrm{C}$. Forging process was finished at temperatures $900^{\circ} \mathrm{C}, 975^{\circ} \mathrm{C}$, and $1050^{\circ} \mathrm{C}$. Microstructure examination and hardness measurement were carried out for forged steels. Mechanical properties and impact measurements were carried out for quenched tempered steels. Ti addition was found to have significant influence on refinement of grains and increase of ferrite/pearlite ratio. It was also, observed that grain size decreases as finishing temperature of forging process decreases. Both Ti addition and lowering finishing forging temperature have positive effect on hardness. In addition, results indicated that addition of titanium has significant effect on the mechanical properties and toughness.
\end{abstract}

Keywords: Titanium; Refinement; Ferrite; Pearlite; Forging

\section{Introduction}

Mechanical properties of steels are strongly connected to their microstructure obtained after heat treatments that are generally performed in order to achieve a good hardness and/or tensile strength with sufficient ductility [1].

Microalloyed steels have been developed for many years and are widely used in modern industry. It is well known that microalloyed high-strength low-alloy steels are essentially carbon low-alloy steels that contain small additions of alloying elements such as $\mathrm{Nb}, \mathrm{V}$, or Ti [2-6]. These elements act as solution atoms or precipitation to suppress the recrystallization and grain growth of austenite. Microalloying of carbon steels is widely used in practice. At the same time, little attention has been given to medium carbon steels containing vanadium, niobium and titanium.

The obtained fine grain microstructure can enhance the mechanical properties of steels obviously. In addition, multimicroalloying can lead to the formation of carbide and nitride particles which can further influence on the mechanical properties of steels [7-10].

Due to the high price of niobium and vanadium, the development of titanium microalloyed steels seems to be attracted and get more attention recently.

Steel alloyed with titanium alone especially the formation mechanism of $\mathrm{TiC}$ precipitation during different

*Corresponding author. processes and its effect are seldom studied in carbon steel.

This work aims at investigating the influence of titanium additions in medium carbon steels on mechanical properties and also investigation of the effect of finishing forging temperatures on grain refinements.

\section{Experimental}

Four steels with different titanium contents were melted in induction furnace of capacity $100 \mathrm{~kg}$ and cast in sand mold. Complete chemical analysis has been carried out for all cast steels. Ingots with diameter $90 \mathrm{~mm}$ were hot forged to about $40 \mathrm{~mm}$ square. The ingots were reheated up to $1200^{\circ} \mathrm{C}$ and hold to 30 min then start forging. Starting forging temperature was $1150^{\circ} \mathrm{C}$ while forging process was ended at temperatures $900^{\circ} \mathrm{C}, 975^{\circ} \mathrm{C}$, and $1050^{\circ} \mathrm{C}$ for the four steels. Microstructure examination and hardness measurements were carried out after forging process. Ferrite/pearlite ratios were measured using software Paxit program for forged steels. The forged bars - which ended at $975^{\circ} \mathrm{C}$-were reheated up to $960^{\circ} \mathrm{C}$ for 1 hour and water-cooled followed by tempering at $260^{\circ} \mathrm{C}$ for $30 \mathrm{~min}$. The mechanical properties were measured for tempered steels. The standard V-notch Charpy specimens samples $(10 \mathrm{~mm} \times 10 \mathrm{~mm} \times 55 \mathrm{~mm}$, notch depth $2 \mathrm{~mm})$ was prepared to investigate the influence of the titanium addition on impact toughness at $25^{\circ} \mathrm{C}$ for tempered steels. 


\section{Results}

The melted steels have the chemical composition given in Table 1. The microstructure examination of forged steels at finishing temperatures $900^{\circ} \mathrm{C}, 975^{\circ} \mathrm{C}$, and $1050^{\circ} \mathrm{C}$ is given in Figures 1-3 respectively.

It is clear that the grain size decreases as titanium content increases at finished forging temperature $900^{\circ} \mathrm{C}$ as illustrated in Figure 1. This can be attributed to the presence of titanium forming titanium carbides and/or titanium nitrides on the austenite grains that retard the grains growth and hence grain of ferrite decrease. The same results observed at finishing forging temperatures $975^{\circ} \mathrm{C}$ and $1050^{\circ} \mathrm{C}$ as shown in Figures 2 and 3. However, it was observed that for the same steel, the grain size increase by increasing the finishing forging temperature. This can be due to the grain growth of austenite phase during forging process and hence the ferrite and pearlite grain size increase. Also, it may be due to the solubility of titanium in austenitic phase increase as temperature increases leading to decrease of $\mathrm{TiC}$ formation which suppress the growth of austenitic grains.

The microstructure examination show that the ferrite/pearlite ratio increases by increasing titanium content. This can be attributed to the formation of titanium carbides and consequently the free carbon is decreased leading to the increase of ferrite/pearlite ratio.

Table 1. Chemical composition of melted steels.

\begin{tabular}{cccccccc}
\hline & \multicolumn{7}{c}{ Chemical composition (\%) } \\
\cline { 2 - 8 } Type & $\mathrm{C}$ & $\mathrm{Si}$ & $\mathrm{Mn}$ & $\mathrm{P}$ & $\mathrm{S}$ & $\mathrm{Cr}$ & $\mathrm{Ti}$ \\
\hline T0 & 0.301 & 0.108 & 1.13 & 0.040 & 0.030 & 0.401 & 0.0015 \\
$\mathrm{~T} 1$ & 0.277 & 0.083 & 1.01 & 0.030 & 0.013 & 0.404 & 0.0485 \\
$\mathrm{~T} 2$ & 0.275 & 0.104 & 1.04 & 0.033 & 0.019 & 0.414 & 0.0997 \\
T3 & 0.296 & 0.110 & 1.02 & 0.034 & 0.015 & 0.409 & 0.2300 \\
\hline
\end{tabular}
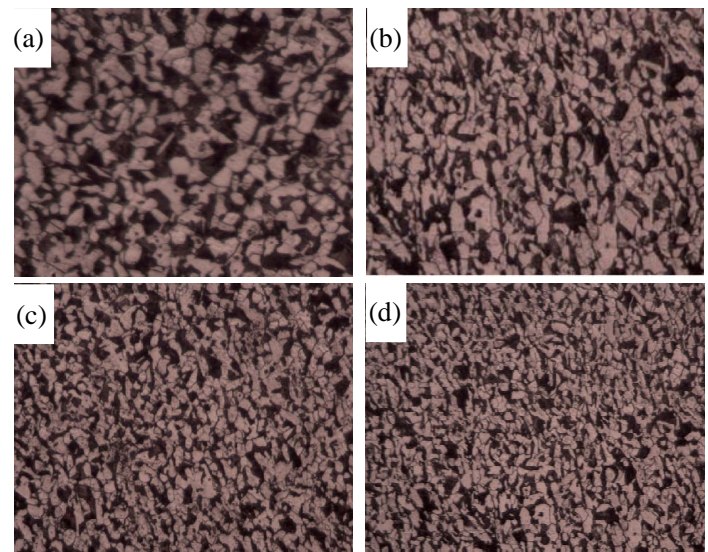

Figure 1. Microstructure of forged steels at finishing forging temperature $900^{\circ} \mathrm{C}((\mathrm{a})$ reference steel $0.0015 \% \mathrm{Ti}$, (b) $0.0485 \% \mathrm{Ti}$, (c) $0.0997 \% \mathrm{Ti}$, (d) $0.230 \% \mathrm{Ti}$ ) $-\mathrm{X} 400$.
However the finished forging temperature has little influence on the ferrite/pearlite ratios as illustrated in Table 2 .

It is clear from Table 2 that ferrite percentage increases from $10 \%$ to $12 \%$ as titanium content increases from $0.0015 \%$ to $0.2300 \%$. While, there is little change in ferrite/pearlite ratio that results from finishing temperatures of forging.
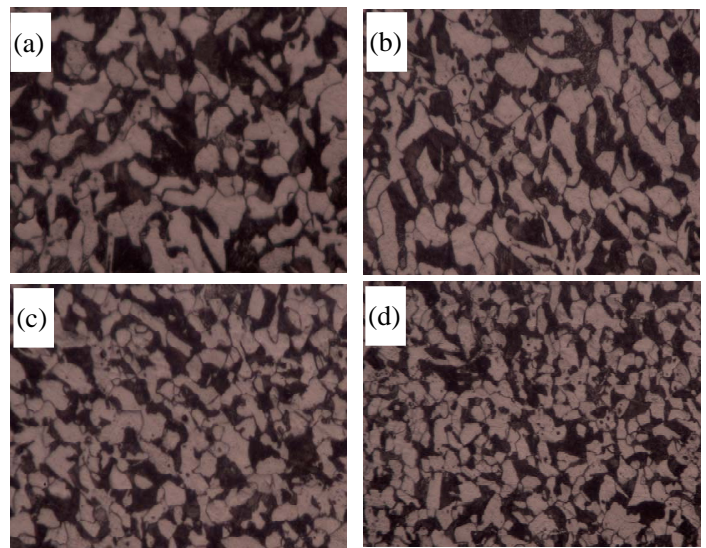

Figure 2. Microstructure of forged steels at finishing forging temperature $975^{\circ} \mathrm{C}$ ((a) reference steel (b) $0.0485 \% \mathrm{Ti}$, (c) $0.0997 \% \mathrm{Ti}$, (d) $0.230 \% \mathrm{Ti})-\mathrm{X} 400$.
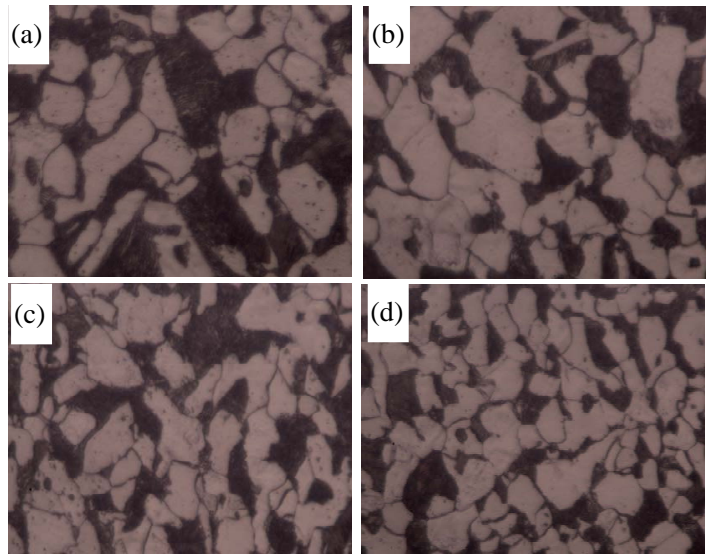

Figure 3. Microstructure of forged steels at finishing forging temperature $10500^{\circ} \mathrm{C}((\mathrm{a})$ reference steel (b) $0.0485 \% \mathrm{Ti}$, (c) $0.0997 \% \mathrm{Ti}$, (d) $0.230 \% \mathrm{Ti})-\mathrm{X} 400$.

Table 2. Show ferrite percentage of different $\mathrm{Ti}$ steel grades at different finishing forging temperature.

\begin{tabular}{cccc}
\hline & & \multicolumn{2}{c}{ Ferrite (\%) at temperature $\left({ }^{\circ} \mathrm{C}\right)$} \\
\cline { 2 - 4 } Type & 900 & 975 & 1050 \\
\hline Ti 0 & 68.28 & 65.02 & 63.13 \\
Ti 1 & 69.46 & 70.94 & 69.12 \\
Ti 2 & 73.53 & 71.78 & 70.01 \\
Ti 3 & 78.21 & 76.95 & 75.12 \\
\hline
\end{tabular}


The results show that the hardness increases by increasing titanium content for each finishing forging temperatures and increases by decreasing the finishing of forging temperature as illustrated in Figure 4. Therefore, it is clear that the main controlling parameter for hardness is the grain refinement.

Titanium content has great influence on mechanical properties of steels, where it was noticed that the yield and ultimate tensile strength increase by increasing titanium content but elongation decreases as given in Figure 5. This can be attributed to the effect of grain refinement of titanium.

Impact toughness is of importance for the evaluation of the resistance capability of steel against the crack initiation and rupture. In general, it is of significant evidences that the addition of low alloy element (such as V, $\mathrm{Ti}$, and $\mathrm{Ni}$, etc.) [11-12].

Titanium is used to retard grain growth and thus improve toughness as it is clear from Figure 6.

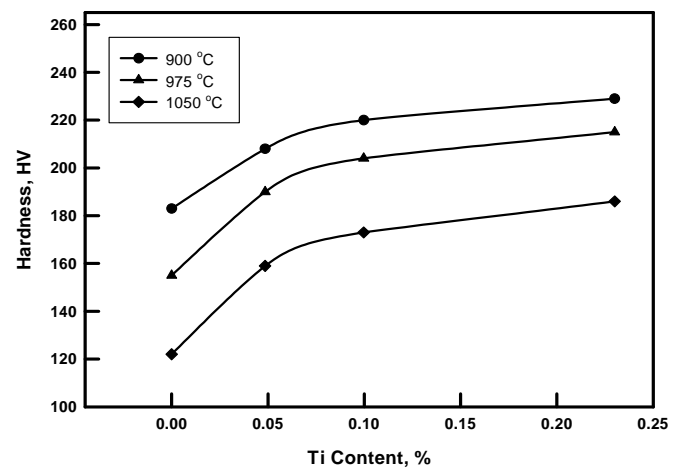

Figure 4. Variation of hardness with titanium content at different finishing forging temperatures.

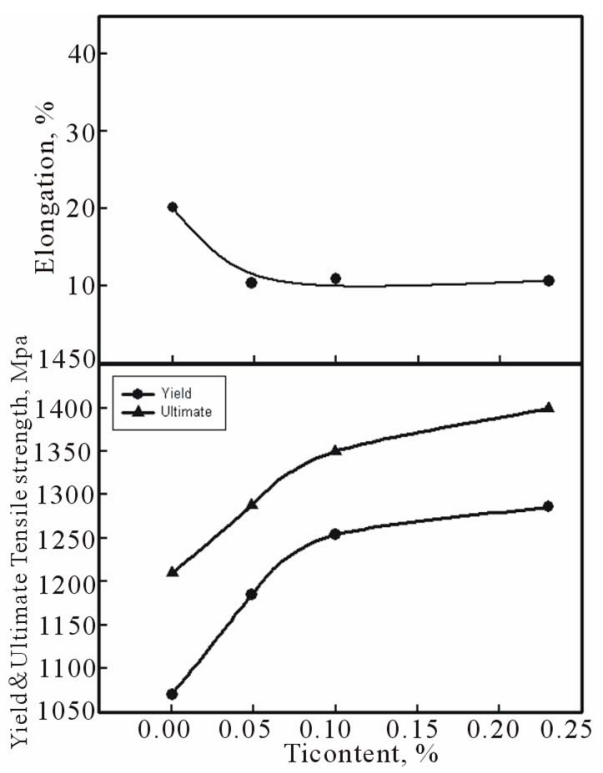

Figure 5. Yield, ultimate tensile strength and elongation of tempered steels with different titanium content.
The relation between the solubility products of carbides and nitrides as a function of temperature illustrated by Aronsson [13] is given in Figure 7. From this figure, it is clear that the solubility product of $\mathrm{TiC}$ in austenitic phase increases by increasing temperature from $770^{\circ} \mathrm{C}$ to $1050^{\circ} \mathrm{C}$.

From the results given in this figure the solubility of titanium at this temperature range can be calculated and is given in Table 3. From this table, it is clear that the solubility of titanium increases by increasing temperature. Consequently, TiC will decreases by increasing temperature in the austenitic phase. As, there is a direct effect of $\mathrm{TiC}$ on the formed ferrite grain size, therefore by decreasing temperature the ferrite grain size decreases. The actual atomic mole fraction of $\mathrm{Ti}$ and its solubility product of four types of steels is given in Table 4 .

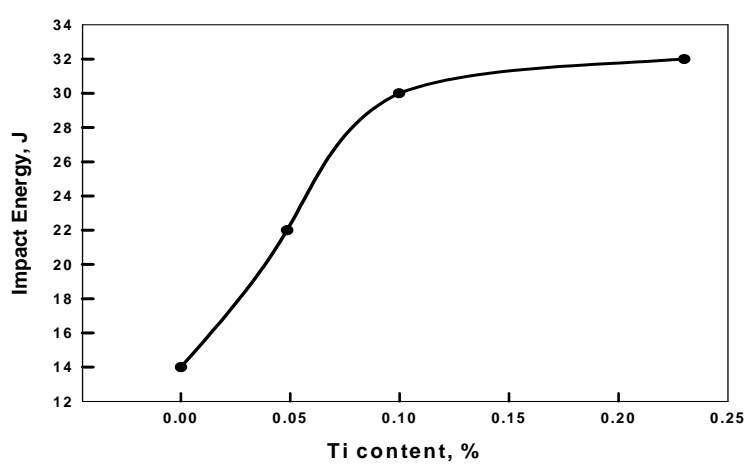

Figure 6. Impact energy of tempered steels at different titanium content.

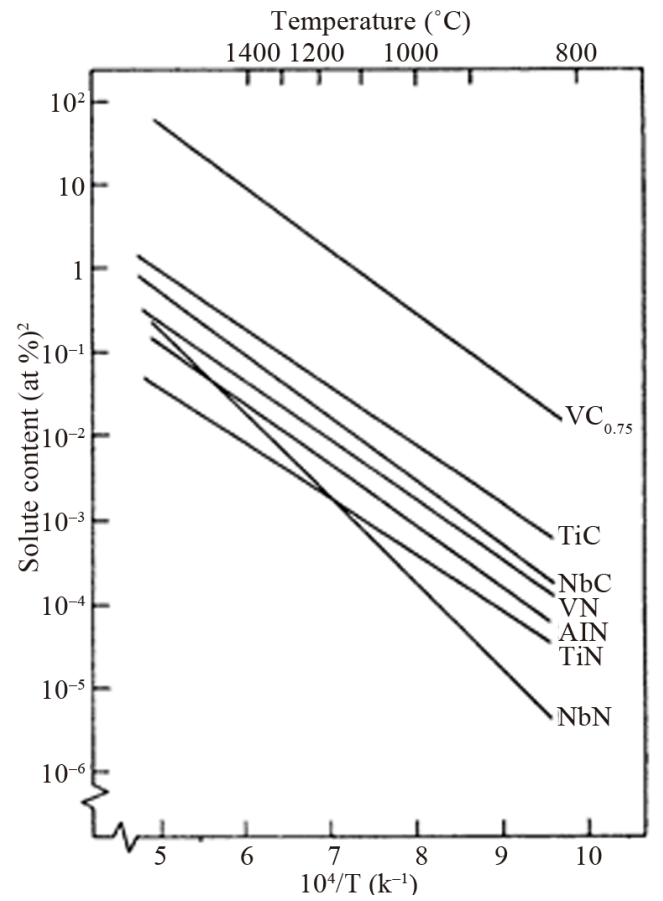

Figure 7. Solubility products of carbides and nitrides in austenite as a function of temperature [13]. 
Table 3. The predicted solubility and solubility product of TiC with temperature according to Aronsson [13].

\begin{tabular}{ccccc}
\hline Temp K & $10000 / \mathrm{T}(\mathrm{K})$ & Intercept & $\begin{array}{c}\text { Solubility } \\
\text { product }\left(\mathrm{S}^{2}\right)\end{array}$ & $\begin{array}{c}\text { Solubility (S) Atomic } \\
\text { (mole fraction) \% }\end{array}$ \\
\hline 1173 & 8.525149 & 2.8807 & 0.317188 & 0.563194 \\
1248 & 8.012821 & 2.8807 & 0.471245 & 0.686473 \\
1323 & 7.558579 & 2.8807 & 0.607835 & 0.779638 \\
1073 & 9.319664 & 2.8807 & 0.078277 & 0.27978 \\
1053 & 9.496676 & 2.8807 & 0.025049 & 0.15827 \\
1044 & 9.578544 & 2.8807 & 0.000432 & 0.02078 \\
1043 & 9.587728 & 2.8807 & -0.00233 & - \\
\hline
\end{tabular}

Table 4. Actual solubility and solubility product of investigated steels.

\begin{tabular}{ccc}
\hline Type & Ti mole Fraction & Solubility product \\
\hline Ti 0 & 0.0017 & $2.972 \mathrm{E}-06$ \\
Ti 1 & 0.0559 & $3.124 \mathrm{E}-03$ \\
Ti 2 & 0.1148 & $1.318 \mathrm{E}-02$ \\
Ti 3 & 0.2644 & $6.992 \mathrm{E}-02$ \\
\hline
\end{tabular}

Figure 7 and Table 3 show that the formation of TiC is function in temperature of austenitic phase. Solubility of $\mathrm{Ti}$ decreases by increasing temperature as indicated from decreasing of solubility and solubility product. The solubility of $\mathrm{Ti}$ at $770^{\circ} \mathrm{C}$ equal zero that is mean that any Ti content must form TiC. At $800^{\circ} \mathrm{C}$ the solubility is $0.27978 \%$ atom. This means that any titanium content less than $0.2797 \%$ atomic present as soluble and start to form $\mathrm{TiC}$ by decreasing temperature. This means that the grain refinement is controlled at stage of cooling above and near to Ac3, Ti \& C content.

Actually, this study shows that the grain growth is restricted as finishing forging temperature decreased (from $1050^{\circ} \mathrm{C}$ to $900^{\circ} \mathrm{C}$ ). But, Ti content has positive effect on grain refinement at high temperature (up to $1050^{\circ} \mathrm{C}$ ). The later need to more investigation in future work.

\section{Conclusions}

The addition of titanium has great influence on grain refinement and hence has positive effect on hardness, mechanical properties, and impact toughness. The grain refinement increases as finished forging temperature decreases from $1050^{\circ} \mathrm{C}$ to $900^{\circ} \mathrm{C}$ passing through $975^{\circ} \mathrm{C}$.

Ferrite/pearlite ratio increase as titanium content increase from $0.0015 \%$ to $0.2300 \%$. The finishing forging temperature has little negative influence on ferrite/pearlite ratio. The precipitation of $\mathrm{TiC}$ is took place in temperature above and close to Ac3.

\section{REFERENCES}

[1] N. Mebarki, D. Delagnes, P. Lameise, F. Delimas and C. Levaillant, "Relationship between Microstructure and Mechanical Properties of a 5\% Cr Tempered Martensitic Tool Steel," Materials Science and Engineering: A, Vol. 387-389, 2004, pp. 171-175. doi:10.1016/j.msea.2004.02.073

[2] P. Ghosh, R. K. Ray, C. Ghosh and D. Bhattacharjee, "Comparative Study of Precipitation Behavior and Texture Formation in Continuously Annealed $\mathrm{Ti}$ and $\mathrm{Ti}+\mathrm{Nb}$ Added Interstitial-Free High-Strength Steels,” Scripta Materialia, Vol. 58, No. 11, 2008, pp. 939-942.

doi:10.1016/j.scriptamat.2008.01.056

[3] S. G. Hong, H. J. Jun, K. B. Kang and C. G. Park, "Evolution of Precipitates in the Nb-Ti-V Microalloyed HSLA Steels during Reheating," Scripta Materialia, Vol. 48, No. 8, 2003, pp. 1201-1206. doi:10.1016/S1359-6462(02)00567-5

[4] P. Ghosh, C. Ghosh and R. K. Ray, "Thermodynamics of Precipitation and Textural Development in Batch-Annealed Interstitial-Free High-Strength Steels,” Acta Materialia, Vol. 58, No. 11, 2010, pp. 3842-3850. doi:10.1016/j.actamat.2010.03.048

[5] J. K. Oduksote, T. K. Ajiboye and A. B. Rabiu, "Evaluation of Mechanical Properties of Medium Carbon Steel Quenched in Water and Oil," Journal of Minerals and Materials Characterization and Engineering, Vol. 11, No. 9, 2012, pp. 859-862.

[6] T. Senthilkumar and T. K. Ajiboye, "Effect of Heat Treatment Processes on the Mechanical Properties of Medium Carbon Steel," Journal of Minerals and Materials Characterization and Engineering, Vol. 11, No. 2, 2012, pp. 143-152.

[7] A. J. Craven, K. He, L. A. J. Garvie and T. N. Baker, "Complex Heterogeneous Precipitation in Titanium-Niobium Microalloyed Al-killed HSLA Steels: I. (Ti,Nb)(C,N) Particles,” Acta Materialia, Vol. 48, No. 15, 2000, pp. 3857-3868. doi:10.1016/S1359-6454(00)00194-4

[8] K. B. Kang, O. Kwon, W. B. Lee and C. G. Park, "Effect of Precipitation on the Recrystallization Behavior of a $\mathrm{Nb}$ Containing Steel,” Scripta Materialia, Vol. 36, No. 11, 1997, pp. 1303-1308. doi:10.1016/S1359-6462(96)00359-4

[9] S. G. Hong, K. B. Kang and C. G. Park, "Strain-Induced Precipitation of $\mathrm{NbC}$ in $\mathrm{Nb}$ and $\mathrm{Nb}-\mathrm{Ti}$ Microalloyed HSLA Steels,” Scripta Materialia, Vol. 46, No. 2, 2002, pp. 163-168. doi:10.1016/S1359-6462(01)01214-3

[10] S. Matsuo, T. Ando and N. J. Grant, "Grain Refinement and Stabilization in Spray-Formed AISI 1020 Steel," Materials Science and Engineering: A, Vol. 288, No. 1, 2000, pp. 34-41. doi:10.1016/S0921-5093(00)00881-9

[11] H. A. Drian and F. B. Pickering, "Effect of Ti Addition on Austenite Grain Growth Kinetics of Medium Carbon V-Nb Steels Containing 0.008\% - 0.18\% N,” Materials Science and Technology, Vol. 7, No. 2, 1991, pp. 176-182. doi:10.1179/026708391790194860

[12] F. Zia-Ebrahimi and G. Krauss, "The Evaluation of Tempered Martensite Embrittlement in 4130 Steel by Instrumented Charpy V-Notch testing," Metallurgical and Ma- 
terials Transactions A, Vol. 14A, No. 6, 1983, pp. 11091119.
[13] Aronsson, "In Steel Strengthening Mechanisms," Climax Molybdenum Co., Michigan, 1969. 